\title{
Anaerobic Degradation of Terephthalic Acid and Aniline by Methanogenic Consortia
}

\author{
KAZUYO YUMIHARA ${ }^{1,2}$, TORU SHIGEMATSU ${ }^{2 *}$, KEISUKE HAMADA $^{2}$, \\ SHIGERU MORIMURA ${ }^{2}$, and KENJI KIDA ${ }^{2,3}$ \\ ${ }^{1}$ Department of Bioengineering, Yatsushiro National College of Technology \\ /2627 Hirayama-shinmachi, Yatsushiro, Kumamoto, 866-8501 Japan. \\ ${ }^{2}$ Department of Materials and Life Science, Graduate School of Science and Technology, \\ Kumamoto University \\ ${ }^{3}$ Department of Applied Chemistry and Biochemistry, Faculty of Engineering, Kumamoto University \\ 12-39-1 Kurokami, Kumamoto-City, Kumamoto 860-8555, Japan
}

\begin{abstract}
The biodegradability of eight aromatic compounds; benzyl alcohol, phenol, toluene, terephthalic acid, aniline, benzensulfonic acid, 2,4,6-trichlorophenol and $m$-nitrophenol; was evaluated under methanogenic conditions. Benzyl alcohol and phenol were termed as readily biodegradable aromatic compounds based on the net gas production. Toluene, terephthalic acid, aniline, and benzenesulfonic acid were termed as persistent compounds. 2,4,6-trichlorophenol and $m$-nitrophenol were caused a toxicity response of the methanogenesis. All compounds, which were suggested to be toxicity compounds by the biodegradability test, showed toxicity to aceticlastic methanogens. The anaerobic continuous treatments of synthetic wastewaters with aniline or terephthalic acid as the carbon sources were carried out. Glucose or acetic acid, used as co-substrates, showed stimulatory effect on the degradation of aniline or terephthalic acid. The degradation efficiency of aniline and terephthalic acid were more than $80 \%$ and $90 \%$, respectively, in the treatments of synthetic wastewaters with acetic acid and aniline or terephthalic acid at the mole ratio (acetic acid / aniline or terephthalic acid) over 10.0 at a TOC loading rate of $0.5 \mathrm{~g} / l \cdot \mathrm{d}$.
\end{abstract}

Key words: terephthalic acid, aniline, anaerobic degradation, methane fermentation

\section{INTRODUCTION}

Significant amounts of aromatic compounds are present in the wastewaters discharged from the petrochemical factories. The biodegradation of aromatic compounds is of interest based on their toxicity to human health. Aniline (aminobenzene) is one of the harmful compounds and its concentration in wastewater is restricted in Japan ". This compound is used as the standard compound for MITI Biodegradation Test (OECD 301C) ${ }^{2}$. Terepthalic acid (1,4-benzendicarboxic acid) is aromatic compound that used in the production of poly (ethylene terephthalate, PET) bottle, and is one of the top 50 chemicals manufactured in the world. ${ }^{3)}$ A significant amount of terephthalic acid is discharged from PET bottle producing process or purification of terephthalic acid.

Methane fermentation process, or microbial degradation of organic matters under anaerobic conditions, has been regarded as an energy-saving wastewater treatment process. However, the introduction of the anaerobic processes for wastewater containing aromatic compounds has been recognized to be difficult, because of their

* Corresponding Author 
presumed toxicity and poor biodegradability. Recently, it has been clear that most aromatic compounds can be degraded under anaerobic conditions, such as methanogenic and /or sulfate-reducing conditions." Based on these findings, application of anaerobic treatment on wastewaters including aromatic compounds is expected. But there are only a few reports on the anaerobic biodegradation of terephthalic acid and aniline or on the construction of treatment processes..$^{5-7)}$

Kawahara et al. carried out the anaerobic biodegradability tests of 13 compounds, and demonstrated that 5 aromatic compounds showed persistent under methanogenic conditions $^{8)}$. We estimated here, therefore, the biodegradability of eight aromatic compounds with different functional groups including aniline $\left(-\mathrm{NH}_{2}\right)$ and terephthalic acid $(-\mathrm{COOH})$ under methanogenic conditions. We also estimated and their toxicity to aceticlastic methanogenesis. Then, we constructed two continuous anaerobic treatments decomposing aniline or terephthlate, which both showed no toxicity to aceticlastic methanogenesis but showed low degradability under methanogenic conditions. Moreover, we estimated the stimulative effect of glucose or acetate on the anaerobic biodegradations of the two aromatic compounds.

\section{MATERIALS AND METHODS}

Synthetic wastewater A modified methanothrix medium (DSMZ medium 334 provided by Deutsche Sammlung von Mikroorganismen und Zellkulturen $\mathrm{GmbH}$ [DSMZ], Braunschweig, Germany) was prepared for synthetic acetate wastewater without $\mathrm{Ni}^{2+}$ and $\mathrm{Co}^{2+}$ as follows $(\mathrm{g} / l)$ : sodium acetate, 5.46; acetic acid, $16.0 ; \mathrm{KH}_{2} \mathrm{PO}_{4}, 0.3$; $\mathrm{KHCO}_{3}, 4.0 ; \mathrm{NH}_{4} \mathrm{Cl}, 1.0 ; \mathrm{NaCl}, 0.6 ; \mathrm{MgCl}_{2}$. $6 \mathrm{H}_{2} \mathrm{O}, 0.82 ; \mathrm{CaCl}_{2} \cdot 2 \mathrm{H}_{2} \mathrm{O}, 0.08$; cystein- $\mathrm{HCl} \cdot$ $\mathrm{H}_{2} \mathrm{O}, 0.1 ; 10 \mathrm{ml}$ of trace element solution without $\mathrm{Ni}^{2+}$ and $\mathrm{Co}^{2+}$; and $10 \mathrm{ml}$ of vitamin solution without $\mathrm{B}_{12}$. $\mathrm{NiCl}_{2} \cdot 6 \mathrm{H}_{2} \mathrm{O}$ and $\mathrm{CoCl}_{2}$. $6 \mathrm{H}_{2} \mathrm{O}$ were added to give $\mathrm{Ni}^{2+}$ and $\mathrm{Co}^{2+}$ concentrations of 0.5 and $0.2 \mathrm{mg} / l$, respectively. The TOC concentration of the synthetic wastewater was $4,000 \mathrm{mg} / l$.

The acclimatized digested sludge Mesophilic digested sludge from Kumamoto-
Tobu sewage works (Kumamoto-city) was introduced into a completely stirred tank reactor MD-500 (Marubishi, Tokyo) with a working volume of $10 \mathrm{l}$. This sludge was then acclimatized with a mixed sludge, 2:1 mixture of primary sludge and thickened surplus sludge, in an organic matter loading rate of $1.0 \mathrm{~g} / l \cdot \mathrm{d}$ by draw and fill method ${ }^{9)}$ at $37^{\circ} \mathrm{C}$ for 6 months.

Aceticlastic methanogenic sludge The acclimatized digested sludge was washed and diluted with the synthetic acetate wastewater to give a final $\mathrm{OD}_{660}$ of 3.0. A $0.4 l$ of the resulting sludge was introduced into a completely stirred tank reactor MD-300 (Marubishi, Tokyo) with a working volume of $3 l$. The continuous cultivation of the sludge was carried out at $37^{\circ} \mathrm{C}$ supplied with the synthetic acetate wastewater at a dilution rate of $0.6 \mathrm{~d}^{-1}$ for one year. Phase contrast microscopic observation of the culture broth was carried out using type BX60 (Olympus, Tokyo).

Biodegradability test of aromatic compounds under methanogenic conditions A $90 \mathrm{ml}$ of non organic salts medium (in $1 l$; $\mathrm{KH}_{2} \mathrm{PO}_{4}, \quad 0.27$ g; $\mathrm{Na}_{2} \mathrm{HPO}_{4} \cdot 12 \mathrm{H}_{2} \mathrm{O}, 1.12 \mathrm{~g}$; $\mathrm{NH}_{4} \mathrm{Cl}, 0.53 \mathrm{~g} ; \mathrm{CaCl}_{2} \cdot 2 \mathrm{H}_{2} \mathrm{O}, 0.075 \mathrm{~g} ; \mathrm{MgCl}_{2}$. $2 \mathrm{H}_{2} \mathrm{O}, 0.10 \mathrm{~g} ; \mathrm{FeCl}_{2} \cdot 4 \mathrm{H}_{2} \mathrm{O}, 0.20$ g; resazurin, $0.001 \mathrm{~g}$ ) which was purged with nitrogen gas, mixed with a $10 \mathrm{ml}$ of the acclimatized digested sludge, was introduced into a $125 \mathrm{ml}$ serum bottle capped with a butyl rubber stopper. Aromatic compound of interest was, then, added to give a total organic carbon (TOC) concentration of $100 \mathrm{mg} / \mathrm{l}$ and was incubated at $37{ }^{\circ} \mathrm{C}$ for 8 weeks according to the method by Kawahara et al. ${ }^{8}$. Biogas production, due to the complete degradation of the aromatic compound, is theoretically calculated to be approximately $21 \mathrm{ml}$ at $37^{\circ} \mathrm{C}$. Produced biogas was measured on every week.

Toxicity test of the aromatic compounds to aceticlastic methanogens The toxicity of persistent compounds to aceticlastic methanogens were estimated as follows. A $0.2 \mathrm{ml}$ of $298.6 \mathrm{mg} / \mathrm{l}$ sodium acetate solution was introduced into a $15 \mathrm{ml}$ serum bottle. Next, a $0.2 \mathrm{ml}$ of the test compound solution were added to final concentrations of 50,100 or $200 \mathrm{mg} / \mathrm{l}(20 \mathrm{mg} / \mathrm{l}$ was adapted for $\mathrm{m}$ - 
nitrophenol). A $15 \mathrm{~mm}$ stirrer bar was put to each serum bottle, which was then tightly capped with a rubber stopper and screw cap.

Nitrogen gas was purged for one minute into the headspace with a syringe needle. After connecting a $3 \mathrm{ml}$ volumetric pipette using vinyl tubes, the bottles were placed in a water bath at $37^{\circ} \mathrm{C}$ and left for $1-2 \mathrm{hrs}$. A 10 $\mathrm{m} l$ of aceticlastic methanogenic sludge was added into the bottle and incubated with mixing at $37^{\circ} \mathrm{C}$. After one hour of incubation, the gas production volume was measured at $0.5 \mathrm{~h}$ intervals manually. The relative gas production volume in the presence and absence of the test substance was compared and the toxicity effect of the test compounds to the aceticlastic methanogenic sludge was determined.

Continuous treatment test using UAFP (Upflow anaerobic filter process) bioreactor system UAFP bioreactor system used in this report is glass with a working volume of $0.78 l$ (Fig. 1). The apparatus for the UAFP was described previously ${ }^{10)}$. The acclimatized digested sludge was circulated in the reactor for one over night to allow the microorganisms attach the carrier. Then, the synthetic wastewater, shown in Table 1,2 , was added continuously at a TOC loading rate of $0.5 \mathrm{~g} / l \cdot \mathrm{d}$ for the synthetic wastewater with multiple carbon sources, $0.38 \mathrm{~g} / l \cdot \mathrm{d}$ for the synthetic wastewater with aniline, or 0.29 or $0.58 \mathrm{~g} / l \cdot \mathrm{d}$ for the synthetic wastewater with terephthalic acid. Glucose or acetic acid as easily biodegradable substrate was added to the synthetic wastewater at mole ratios of $0-35$ to the test compound. The treatments were carried out over 200 days for each carbon sources; aniline and glucose, aniline and acetic acid, terephthalic acid and glucose, or terephthalic acid and acetic acid.

In order to estimate the amount of aniline and terephthalic acid absorbed in the microorganisms, the solid fraction in the effluent was treated by ultrasonic and the concentration of aniline in the solid fraction was measured. A $5 \mathrm{~m} l$ of the effluent was centrifuged at $6,500 \mathrm{rpm}$ for $10 \mathrm{~min}$. The pellet was washed twice by ice chilled sterilized water and resuspended in sterilized water to give an $\mathrm{OD}_{660}$ of 3.5 . A $1 \mathrm{ml}$ of resulting solution was then introduced into a
$2 \mathrm{ml}$-volume polypropylene tube with $1 \mathrm{~g}$ of glass beads $(5 \mathrm{~mm} \phi)$ and then beads-beating was carried out for 15 min using Mini-BeadBeater-8 (Central Kagaku, Tokyo). The cell lysate was centrifuged at $10,000 \mathrm{rpm}$ for 30

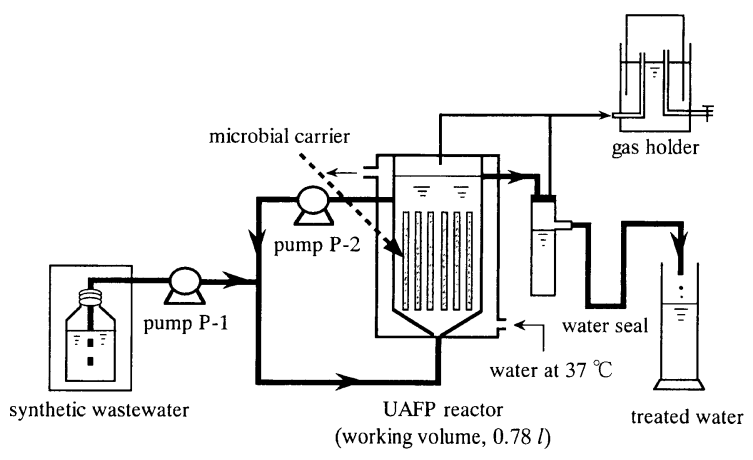

Fig. 1 Schematic diagram of equipment used for upflow anaerobic filter process (UAFP) used for the continuous treatment tests

Table 1 Compositions of the synthetic wastewater for continuous treatment test

Carbon sources

glucose $(4.7 \mathrm{~g} / l)$, aniline $(0.5 \mathrm{~g} / l)$, terephthalic acid $(0.5,1.0 \mathrm{~g} / l)$, or multiple carbon sources ${ }^{\mathrm{a})}$ (aniline + glucose, aniline + acetic acid, terephthalic acid + glucose, or terephthalic acid + acetic acid)

Mineral nutrients

\begin{tabular}{|c|c|}
\hline $\mathrm{K}_{2} \mathrm{HPO}_{4}$ & 3.48 \\
\hline $\mathrm{KH}_{2} \mathrm{PO}_{4}$ & 0.435 \\
\hline $\mathrm{NH}_{4} \mathrm{Cl}$ & 0.056 \\
\hline $\mathrm{MgCl}_{2} \cdot 6 \mathrm{H}_{2} \mathrm{O}$ & 0.045 \\
\hline $\mathrm{NaCl}$ & 0.125 \\
\hline $\mathrm{CaCl}_{2} \cdot 2 \mathrm{H}_{2} \mathrm{O}$ & 0.1 \\
\hline $\mathrm{FeSO}_{4} \cdot 6 \mathrm{H}_{2} \mathrm{O}$ & 0.0001 \\
\hline $\mathrm{Na}_{2} \mathrm{~S} \cdot 9 \mathrm{H}_{2} \mathrm{O}$ & 0.02 \\
\hline Vitamin solution $^{\mathrm{b})}$ & 1.0 \\
\hline Trace element solution" & 0.3 \\
\hline $\mathrm{pH}$ & 7.6 \\
\hline
\end{tabular}

a) The concentrations of each carbon sources for the wastewater containing multiple carbon sources are shown in Table 2.

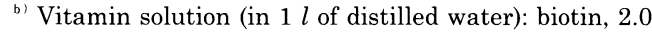
$\mathrm{mg}$; folic acid, $2.0 \mathrm{mg}$; pyridoxine $\cdot \mathrm{HCl}, 10.0 \mathrm{mg}$; thiamine $\cdot \mathrm{HCl}, 5.0 \mathrm{mg}$; riboflavin, $5.0 \mathrm{mg}$; nicotinic acid, $5.0 \mathrm{mg}$; DL-calcium pantothenate, $5.0 \mathrm{mg}$; vitamin $\mathrm{B}_{12}, 0.1 \mathrm{mg} ; p$-aminobenzoic acid, $5.0 \mathrm{mg}$; lipoic acid, $5.0 \mathrm{mg}$.

c) Trace element solution (in $1 \quad l$ of distilled water): $\mathrm{FeCl}_{3}, 1.35 \mathrm{~g} ; \mathrm{MnCl}_{2} \cdot 4 \mathrm{H}_{2} \mathrm{O}, 0.10 \mathrm{~g} ; \mathrm{CoCl}_{2} \cdot 6 \mathrm{H}_{2} \mathrm{O}$, $0.024 \mathrm{~g} ; \mathrm{CaCl}_{2} \cdot 2 \mathrm{H}_{2} \mathrm{O}, 0.10 \mathrm{~g} ; \mathrm{ZnCl}_{2}, 0.10 \mathrm{~g} ; \mathrm{CuCl}_{2}$. $2 \mathrm{H}_{2} \mathrm{O}, 0.025 \mathrm{~g} ; \mathrm{H}_{3} \mathrm{BO}_{3}, 0.01 \mathrm{~g} ; \mathrm{Na}_{2} \mathrm{MoO}_{4} \cdot 2 \mathrm{H}_{2} \mathrm{O}, 0.024$ g; $\mathrm{NaCl}, 1.0 \mathrm{~g} ; \mathrm{NiCl}_{2} \cdot 6 \mathrm{H}_{2} \mathrm{O}, 0.12 \mathrm{~g} ; \mathrm{Na}_{2} \mathrm{SeO}_{3} \cdot 5 \mathrm{H}_{2} \mathrm{O}$, $0.026 \mathrm{~g}$; nitrilotriacetic acid (NTA), $12.8 \mathrm{~g}$. 
min. The supernatant was used for HPLC analysis to detect aniline or terephthalic acid. The beads-beating condition was decided judging from the protein concentration of the supernatant after beads-beating, which was $5,500 \mathrm{mg} / \mathrm{l}$ in the plateau value.

Other analytical methods The TOC concentration and the concentrations of the test compounds in the effluent were measured using the supernatant after centrifugation at $6,000 \times \mathrm{g}$ for $10 \mathrm{~min}$ of the effluent as follows. The concentrations of TOC and inorganic carbon (IC) in the effluent were measured using a TOC analyzer TOC500 (Shimadzu, Kyoto). Volatile fatty acids (VFAs) were analyzed in supernatants obtained after centrifugation at $6,000 \times \mathrm{g}$ for 10 min of the effluent as described previously"'. The methane concentration in the produced biogas was analyzed using a gas chromatography type GC-323 (GL Sciences, Tokyo) equipped with a $2 \mathrm{~m} \times 1 / 8$ " SUS Porapak N 50/80 column (GL Sciences, Tokyo).

The concentrations of aniline, terephthalic acid and phenol in the effluent were determined by reversed-phase high-performance liquid chromatography (Shimadzu model LC-10AT system). Separation was achieved at $35{ }^{\circ} \mathrm{C}$ by using a column of $\mathrm{L}$ column ODS (Chemicals Evaluation Research Institute, Tokyo) at a flow rate of $1.0 \mathrm{~m} l / \mathrm{min}$ in which $0.8 \mathrm{ml} / \mathrm{min}$ of phosphate buffer (20 $\mathrm{mM} \mathrm{Na} \mathrm{HPO}_{4}$ solution mixed with $50 \mathrm{mM}$ $\mathrm{KH}_{2} \mathrm{PO}_{4}$ solution to give a $\mathrm{pH}$ of 7.4) and 0.2 $\mathrm{m} l / \mathrm{min}$ of acetonitrille as the mobile phase. For the separation of terephthalic acid, 0.9 $\mathrm{m} l / \mathrm{min}$ of phosphate buffer and $0.1 \mathrm{ml} / \mathrm{min}$ of acetonitrille were used as the mobile phase.

\section{RESULTS AND DISCUSSION}

Biodegradability of eight aromatic compounds under methanogenic conditions

Biodegradability of eight aromatic compounds, benzyl alcohol, phenol, toluene, terephthalic acid, aniline, benzenesulfonic acid, 2,4,6-trichlorophenol and $m$-nitrophenol (100 mg-C/l) using the acclimatized sludge under methanogenic conditions was estimated based on measuring of the integrated gas production (Fig. 2). The gas production curves of benzyl alcohol and phenol reached a plateau in two to three weeks, being approximately $20 \mathrm{ml}$. The methane concentration of the produced biogas was $60-70 \%$. The gas production curves of toluene, terephthalic acid, aniline and benzenesulfonic acid were similar to the blank curve within eight weeks. These results suggest that benzyl alcohol and phenol are relatively easy to be degraded. On the other hand, toruene, terephthalic acid, aniline and benzenesulfonic acid were suggested to be persistent. The gas production curves of 2,4,6-trichlorophenol and $m$-nitrophenol were shown lower than the blank, suggesting that these compounds caused a toxicity response of the microorganisms in the acclimatized sludge.

Toxicity of on the aromatic compounds to aceticlastic methanogens The toxicity effects of six aromatic compounds, which showed persistent or toxicity by the biodegradation tests, to aceticlastic methanogens were measured based on the specific gas evolution rates using the aceticlastic methanogenic sludge (Fig. 3). Microscopic observation of the aceticlastic methanogenic sludge revealed that Methanosaeta-like organisms and Methanosarcina-like organisms were predominant (data not shown). $200 \mathrm{mg} / \mathrm{l}$ of 2,4,6-trichrolophenol and $20 \mathrm{mg} / \mathrm{l}$ of $\mathrm{m}$ nitrophenol completely inhibited the methanogenesis from acetate. Other compounds and phenol, used as a control, did not inhibit the methanogenesis from acetate even at a high concentration (up to $200 \mathrm{mg} / l$ ).

Anaerobic digestion of organic matters consists of a series metabolism; (i) hydrolysis and acidogenesis, (ii) acetogenesis and dehydrogenation and (iii) methanogenesis ${ }^{11}$. The inhibitory effect of a chemical on anaerobic degradation could depend on its inhibition of single or multiple steps in the series metabolism. In general, methanogenesis from acetate has been recognized the rate-limiting step in anaerobic treatment of soluble organic matters, because there have been several findings that aceticlastic methanogens is the most sensitive to the toxic chemicals ${ }^{12}$. It has been considered that apploximately $70 \%$ of methane is derived from acetate by 
aceticlastic methanogenesis in anaerobic digestion of sewage sludge ${ }^{11.13)}$ and cattle waste $^{(1)}$, and in anoxic sediments of a eutrophic lake ${ }^{15)}$.

In our experiments, $m$-nitrophenol and 2,4,6-trichlorophenol which suggested to be toxicity response in the biodegradability test (Fig. 2), showed a strong toxicity to aceticlastic methanogens (Fig. 3). These results indicate a positive correlation between the toxicity response in the microorganisms in the acclimatized sludge and the toxicity response of aceticlastic methanogens. One possible explanation is that these compound inhibit the anaerobic degradation by their toxicity effect to aceticlastic methanogens.

The degradation of aniline and terephthalic acid in batchwise cultures The biodegradation tests of aniline and terephthalic acid, which showed persistent based on the integrated gas production (Fig. 2) and no toxicity to aceticlastic methanogens (Fig. 3), were carried out. Only 9.8-15.3\% of aniline and $5.1-6.4 \%$ of terephthalic acid were degraded in 56 days incubation, although $100 \%$ of phenol used as a control was degraded (data not shown). However, the degradation efficiencies of aniline and terephthalic acid were improved to 29.2$35.2 \%$ and $12.0-14.7 \%$, respectively, by addition of glucose (data not shown).

The continuous treatment tests of aniline and terephthalic acid As the degradation efficiency of aniline and terephthalic acid in batchwise cultures were very low, the degradation tests by continuous treatment using the UAFP were carried out. The concentrations of TOC and aniline in the soluble fraction of the effluent reached steady states, being $240 \mathrm{mg} / \mathrm{l}$ and $300 \mathrm{mg} / \mathrm{l}$, respectively, after 172 days treatment of the synthetic wastewater with a $500 \mathrm{mg} / \mathrm{l}$ of aniline as the sole carbon source at a TOC loading rate of $0.38 \mathrm{~g} / l \cdot \mathrm{d}$. The removal efficiency of TOC and degradation efficiency of aniline were 37 and $40 \%$, respectively. The concentration of suspended solid (SS) in the effluent was $14.9 \mathrm{~g} / l$ after 172 days continuous treatment. In order to estimate the amount of aniline absorbed in the microorganisms, the solid fraction in the

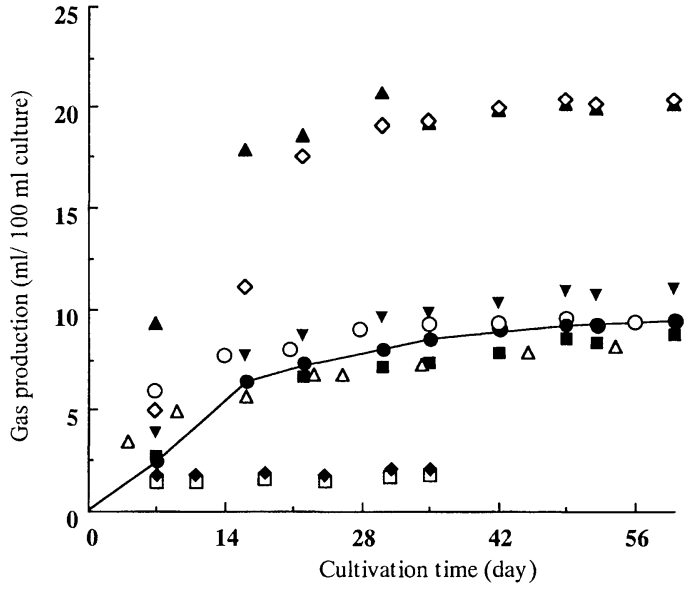

Fig. 2 Integrated gas production caused by degradation of eight aromatic compounds. Symbols: $\boldsymbol{\Delta}$, benzyl alchol; $\diamond$, phenol; toluene; $\bigcirc$, terephthalic acid; $\boldsymbol{\nabla}$, aniline; $\triangle$, benzensulfonic acid; 2,4,6trichlorophenol; $\square$, m-nitrophenol; without addition of test compounds (negative control).

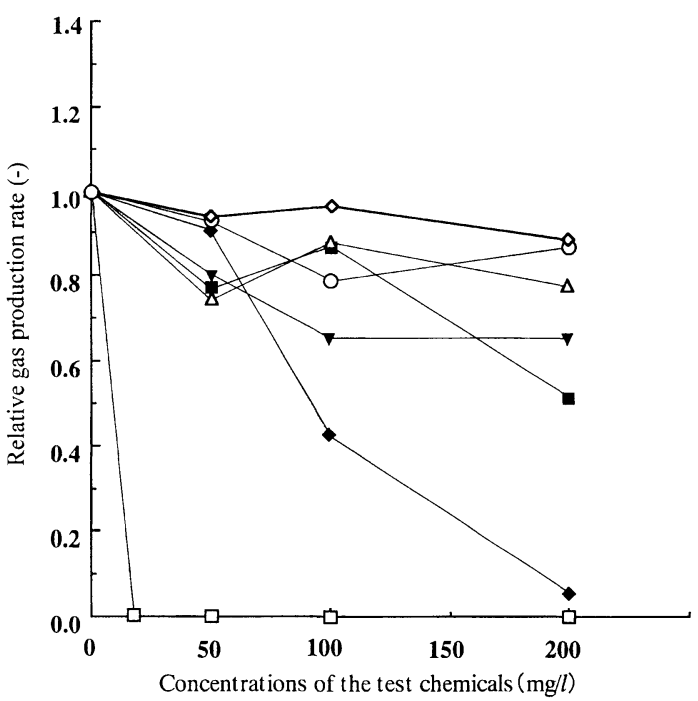

Fig. 3 Toxicity test of aromatic compounds to aceticlastic methanogens based on therelative gas production rate.

Symbols: $\diamond$, phenol; $\square$, toluene; $\bigcirc$, terephthalic acid; $\boldsymbol{\nabla}$, aniline; $\triangle$, benzensulfonic acid; $\diamond, 2,4,6-$ trichlorophenol; $\square$, m-nitrophenol. 
culture broth was treated by ultrasonic and the concentration of aniline in the solid fraction was measured. As the amount of aniline absorbed in SS was $0.064 \mathrm{mg} / \mathrm{g}$-SS, the degradation efficiency of aniline was almost same as that without considering the absorption in SS. The decrease of aniline was suggested to due to degradation by microorganisms in the UAFP.

The continuous treatment test of the synthetic wastewater with terephthalic acid was carried out with 39 days treatment with a $500 \mathrm{mg} / \mathrm{l}$ of terephthalic acid as the sole carbon source at a TOC loading rate of 0.29 $\mathrm{g} / l \cdot \mathrm{d}$, followed by 186 days treatment with a $1,000 \mathrm{mg} / \mathrm{l}$ of terephthalic acid at a TOC loading rate of $0.58 \mathrm{~g} / l \cdot \mathrm{d}$. After the total 225 days treatment, the concentrations of TOC and terephthalic acid in the soluble fraction of effluent reached steady states, being 420 $\mathrm{mg} / \mathrm{l}$ and $680 \mathrm{mg} / \mathrm{l}$, respectively. The removal efficiency of TOC and degradation efficiency of terephthalic acid were 28 and $32 \%$, respectively. The concentration of SS in the effluent was $24.5 \mathrm{~g} / \mathrm{l}$ after 255 days treatment. A $0.8135 \mathrm{mg}$ of terephthalic acid was detected in one gram of SS. The decrease of terephthalic acid was also suggested to due to degradation by microorganisms in the continuous treatment.

The continuous treatment tests of aniline and terephthalic acid with glucose As the degradation efficiency of aniline and terephthalic acid were still low even in the continuous treatments, the influence of the addition of glucose as a co-substrate ${ }^{16)}$ was investigated in the continuous treatment. The mole ratio of glucose and aniline or terephthalic acid was varied as described in Table 2.

Using the steady-state data at each mole ratio, the removal efficiency of TOC and the degradation efficiency of aniline or terephthalic acid were depicted in Fig. 4. The degradation efficiency of aniline increased from 40 to $91 \%$ with an increase in mole ratio of glucose to aniline, and the removal efficiency of TOC was also increased at a

Table 2 Carbon sources in the synthetic wastewaters containing multiple carbon sources for the continuous treatment tests

\begin{tabular}{|c|c|c|c|c|c|c|}
\hline \multicolumn{7}{|l|}{ aniline + glucose } \\
\hline mole ratio (glucose/aniline) & 4.9 & 2.4 & 1.2 & 0.6 & & \\
\hline aniline $(\mathrm{mg} / \mathrm{l})$ & 500 & 500 & 500 & 500 & & \\
\hline glucose $(\mathrm{mg} / \mathrm{l})$ & 4700 & 2350 & 1175 & 588 & & \\
\hline $\mathrm{TOC}(\mathrm{mg} / \mathrm{l})$ & 2270 & 1330 & 860 & 620 & & \\
\hline \multicolumn{7}{|l|}{ terephthalic acid + glucose } \\
\hline $\begin{array}{l}\text { mole ratio } \\
\text { (glucose/terephthalic acid) }\end{array}$ & 8.7 & 4.3 & 2.2 & 1.1 & 0.5 & \\
\hline terephthalic acid $(\mathrm{mg} / \mathrm{l})$ & 500 & 500 & 500 & 500 & 500 & \\
\hline glucose $(\mathrm{mg} / l)$ & 4700 & 2350 & 1175 & 588 & 294 & \\
\hline TOC $(\mathrm{mg} / l)$ & 2170 & 1230 & 760 & 520 & 410 & \\
\hline \multicolumn{7}{|l|}{ aniline + acetic acid } \\
\hline $\begin{array}{l}\text { mole ratio } \\
\text { (acetic acid/aniline) }\end{array}$ & 35.0 & 20.0 & 10.0 & 5.0 & 3.0 & 1.0 \\
\hline aniline $(\mathrm{mg} / \mathrm{l})$ & 500 & 500 & 500 & 500 & 500 & 500 \\
\hline sodium acetate $(\mathrm{mg} / l)$ & 9247 & 5284 & 2642 & 1321 & 792 & 264 \\
\hline acetic acid $(\mathrm{mg} / \mathrm{l})$ & 4515 & 2580 & 1290 & 645 & 387 & 129 \\
\hline $\mathrm{TOC}(\mathrm{mg} / l)$ & 4890 & 2960 & 1680 & 1030 & 770 & 520 \\
\hline \multicolumn{7}{|l|}{ terephthalic acid + acetic acid } \\
\hline $\begin{array}{l}\text { mole ratio } \\
\text { (acetic acid/terephthalic acid) }\end{array}$ & 35.0 & 20.0 & 10.0 & 5.0 & 3.0 & 1.0 \\
\hline terephthalic acid $(\mathrm{mg} / \mathrm{l})$ & 500 & 500 & 500 & 500 & 500 & 500 \\
\hline sodium acetate $(\mathrm{mg} / \mathrm{l})$ & 4407 & 2962 & 1481 & 740 & 444 & 148 \\
\hline acetic acid $(\mathrm{mg} / \mathrm{l})$ & 3226 & 1446 & 723 & 360 & 216 & 72 \\
\hline TOC $(\mathrm{mg} / l)$ & 2870 & 1730 & 1010 & 650 & 510 & 360 \\
\hline
\end{tabular}


A.

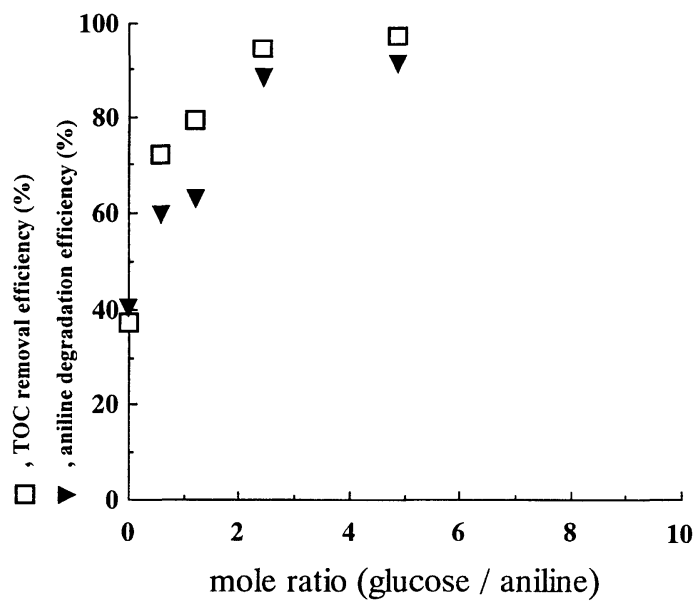

B.

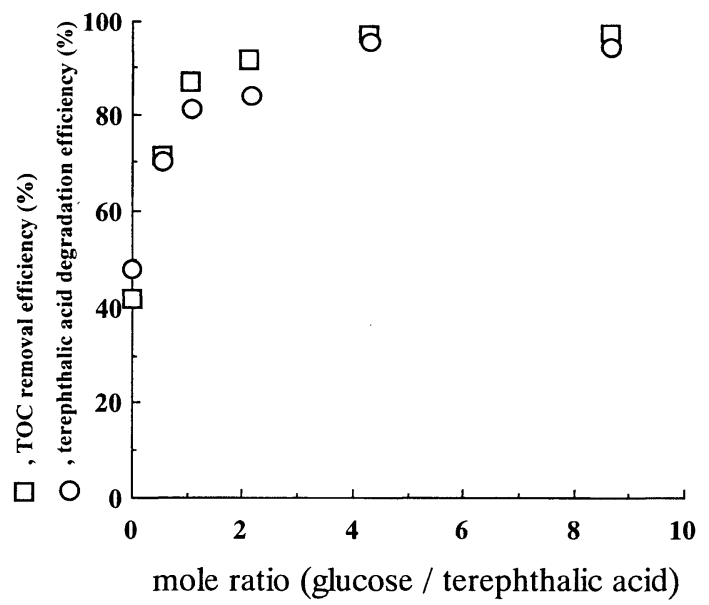

Fig. 4 The degradation efficiency of aniline (A) and terephthalic acid $(B)$ at each mole ratio of glucose to aniline or glucose to terephthalic acid in the continuous treatment tests with addition of glucose. Symbols: $\boldsymbol{\nabla}$, degradation efficiency (\%) of aniline; $\bigcirc$, degradation efficiency (\%) of terephthalic acid; $\square$, removal efficiency $(\%)$ of TOC.

TOC loading rate of $0.5 \mathrm{~g} / l \cdot \mathrm{d}$ as shown in Fig. 4A. The rate of biogas production at a mole ratio of 4.9 was $150-180 \mathrm{ml} / l \cdot \mathrm{d}$. The methane concentration was approximately $50 \%$. The degradation efficiency of terephthalic acid increased from 48 to $95 \%$ with an increase in mole ratio of glucose to terephthalic acid, and the removal efficiency of TOC was also increased at a TOC loading rate of $0.5 \mathrm{~g} / l \cdot \mathrm{d}$ as shown in Fig. 4B. The biogas production rate at a mole ratio of 4.3 was $100-150 \mathrm{ml} / l \cdot \mathrm{d}$. The methane concentration in the biogas was approximately $65 \%$.

These results indicated that addition of glucose improved the biodegradation of aniline or terephthalic acid under continuous treatment drastically compared with the results of batch cultivations.

The continuous treatment tests of aniline and terephthalic acid with acetate In order to investigate the effect of the co-substrate at a simplified condition, acetate was used instead of glucose. The mole ratio of glucose and aniline or terephthalic acid was varied as described in Table 2.

Using the steady-state data at each mole ratio, the removal efficiency of TOC and the degradation efficiency of aniline or terephthalic acid were depicted in Fig. 5. The degradation efficiency of aniline increased from 45 to $90 \%$ with an increase in mole ratio of acetate to aniline, and the removal efficiency of TOC was also increased at a TOC loading rate of $0.5 \mathrm{~g} / l \cdot \mathrm{d}$ as shown in Fig. 5A. The biogas production rate was 80$100 \mathrm{~m} l / l \cdot \mathrm{d}$ and the concentration of acetic acid in the effluent was approximately $58-60 \mathrm{mg} / \mathrm{l}$ at a mole ratio of 10.0. The degradation efficiency of terephthalic acid increased from 85 to $95 \%$ with an increase in mole ratio of acetate to terephthalic acid, and the removal efficiency of TOC was also increased at a TOC loading rate of $0.5 \mathrm{~g} / l \cdot \mathrm{d}$ as shown in Fig. $5 \mathrm{~B}$. The rate of biogas production was 130 $150 \mathrm{ml} / l \cdot \mathrm{d}$ and the methane concentration in the biogas was approximately $60 \%$ under 10.0 mole-ratio conditions. Acetic acid was not detected in the effluents over all moleratio conditions.

Glucose and acetic acid showed stimulative effects for anaerobic degradation of aniline and terephthalic acid, which were suggested as persistent chemicals by the biodegradability test. These results suggest that the additional carbon sources made a change of microbial consortia and/or the metabolic activities of individual cells in the methanogenic sludge 


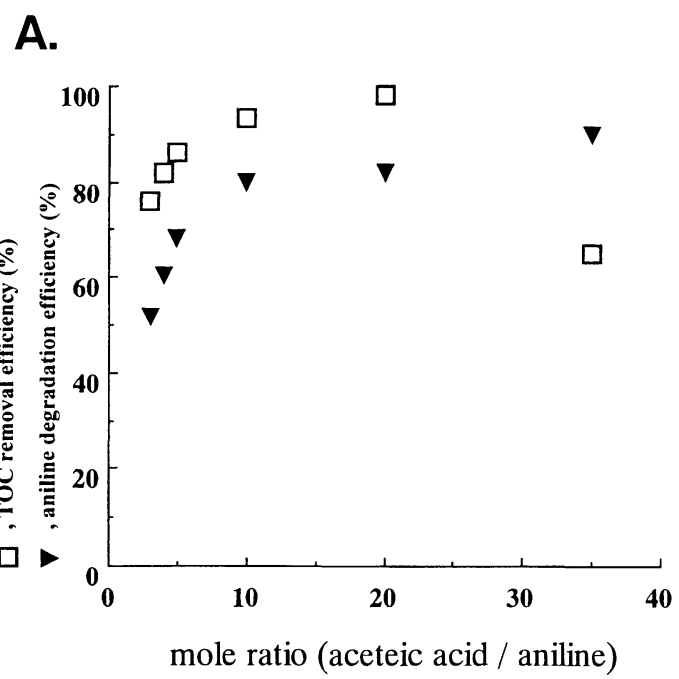

B.

Fig. 5 The degradation efficiency of aniline (A) and terephthalic acid (B) at each mole ratio of acetate to aniline or acetate to terephthalic acid in the continuous treatment tests with addition of acetate. Symbols: $\nabla$, degradation efficiency (\%) of aniline; $\bigcirc$, degradation efficiency (\%) of terephthalic acid; $\square$, removal efficiency $(\%)$ of TOC.

No microorganism capable of degradation of terephthalic acid anaerobically has been isolated. The anaerobic degradation pathway of terephthalic acid is considered as three steps of reactions as follows: (i) the decarboxylation of terephthalic acid causing benzoate $^{6)}$, (ii) acetate and hydrogen production from benzoate ${ }^{17)}$, and (iii) methanogenesis. Kleerebezem et al. reported the inhibition of terephthatlate degradation by acetate using anaerobic batch experiment ${ }^{6)}$. Fajardo et al. reported the inhibition of terephthalic acid degradation by glucose $^{18)}$. These results seem to be different from our finding that acetic acid and glucose showed stimulative effect to anaerobic degradation of terephthalic acid. The difference might be due to the low concentration of glucose or acetate, and/or might be caused by the microbial consortia that the cultures by Kleerebezem or Fajardo consisted of relatively pure microorganisms compared with our culture. In our more complex microbial consortium, a higher population of aceticlastic methanogens or other microorganisms related to degradation of glucose might be needed for the efficient continuous degradation of terephthalic acid. Therefore, additional acetic acid or glucose was suggested to show stimulative effects, although analysis of the microbial flora in the methanogenic consortium is needed for further understanding.

\section{References}

1 ) Chemicals Evaluation and Research Institute: Data sheets of chemical substances regulated by "Law Concerning the Examination and Regulation of Manufacture, etc. of Chemical Substances", Japan Chemical Industry Ecology-Toxicology and Information Center, Tokyo (1992) (in Japanese)

2 ) Organization for Economic Co-operation and Development: Test No. 301: Ready biodegradability, In OECD guidelines for the testing of chemicals/ section 3: degradation and accumulation, OECD, Paris, France (1992)

3 ) Savostianoff, D: TPA-DMT, confidence is coming back, Inf. Chem., 317,193-201 (1990)

4 ) Schink, B., Brune, A., and Schnell, S.: Anaerobic degradation of aromatic compounds. In Microbial degradation of national products, Winkelmann, G. ed., 
VCH:Weinheim, Germany, pp. 219-242 (1990)

5 ) Kleerebezem, R., Huishoff Pol, L. W., and Lettinga, G.: Anaerbic degradation of phthalate isomers by methanogenic consortia, Appl. Environ. Microbiol., 65, 1152-1160 (1990)

6 ) Kleerebezem, R., Hulshoff Pol, L. W., and Lettinga, G.: The role of benzoate in anaerobic degradation of terephthalic acid, Appl. Environ. Microbiol., 65, 11611167(1999)

7 ) Kleerebezem, R., Maarit, I., Hulshoff Pol, L. W., and Lettinga, G.: High - rate treatment of terephthalic acid in anaerobic hybrid reactors, Biotechnol. Prg., 15, 347-357(1999)

8 ) Kawahara, K., Yakabe, Y., Ohide, T., and Kida, K.: Evaluation of laboratory-made sludge for an anaerobic biodegradability test and its use for assessment of 13 chemicals, Chemosphere, 39, 2007-2018 (1999)

9 ) Kida, K., Morimura, S., and Sonoda, Y.: Accumulation of propionic acid during anaerobic treatment of distillery wastewater from barely-shochu making, J. Ferment. Bioeng., 75, 213-216 (1993)

10) Kida, K., Morimura, S., Tadokoro, H., Mashood, S., Yusob, A.A., and Ghin, Y.B.: Treatment of wastewater from rubber thread manufacturing by a combination of chemical and biological process, Environ. Technol., 18, 517-524 (1997)

11) Nagai, S. and Nishio, N.: Biological aspects of anaerobic digestion, pp. 701-752 In Cheremisinoff, N. P.(ed.) "Handbook of heat and mass transfer, vol. 3, Catalysis, kinetics and reactor engineering”, Gulf Publishing Co., Houston, London, Paris,
Tokyo (1989)

12) Speece, R. E. : Chapter X: Toxicity response pp. 245-286 In Anaerobic biotechnology for industrial wastewater., Archae Press, Nashville, TN (1996)

13) Smith, P. H. and Mah, R. A.: Kinetics of acetate metabolism during sludge digestion, Appl. Environ. Microbiol., 14, 368-371 (1966).

14) Mackie, R. I. and Bryant, M. P.: Metabolic activity of fatty acid-oxidizing bacteria and the contribution of acetate, propionate, butyrate, and $\mathrm{CO}_{2}$ to methanogenesis in cattle waste at 40 and $60^{\circ} \mathrm{C}$, Appl. Environ. Microbiol., 41, 13631373 (1981)

15) Lovely, D. R. and Klug, M. J.: Intermediary metabolism of organic matter in the sediments of a eutrophic lake, Appl. Environ. Microbiol., 43, 552560 (1982).

16) Bhatti, Z. I., Toda, H., and Furukawa, K.: Evaluation of second carbon sources for the acclimation and growth of $p$ nitrophenol degrading microbial community, Japanese J. Wat. Treat. Biol., 37, 37-44 (2000)

17) Ellis, L. B. M., Hershberger, C. D., and Wackett, L. P.: The university of Minnesota biocatalysts / Biodegradation database: microorganism genomics and prediction, Nucleic Acid Res., 28, 377-379 (2000)

18) Fajardo, C., Guyot, J. P., Macarie, H., and Monroy, O.: Inhibition of anaerobic digestion by terephthalic acid and its aromatic by product, Water Sci. Technol., 36, 83-90 (1997)

(Submitted 2001. 5. 14)

(Accepted 2001. 10. 17) 